\title{
Modeling the Cost-effectiveness of HIVIAIDS Interventions in Different Socio-economic Contexts in South Africa, (2007-2020)
}

\author{
Josue Mbonigaba1 \\ University of KwaZulu-Natal y \\ E-mail: mbonigaba@ukzn.ac.za
}

Doi:10.5901/mjss.2013.v4n3p587

\begin{abstract}
Evidence on how HIVIAIDS interventions compare on the basis of cost, effectiveness and cost-effectiveness estimates in different socio-economic contexts, has not been sufficient to guide policy-making in South Africa. To guide policy on how HIVIAIDS intervention resources should be allocated in rural and urban contexts, this paper aims to compare, over the period 2007-2020, the cost-effectiveness of intervening in rural and urban contexts for each of the following HIVIAIDS interventions: prevention of mother-to-child transmission (PMTCT), highly active antiretroviral therapy (HAART) for adults and HAART for children. Spectrum Policy Modeling System (SPMS) is used to project effectiveness over time and the number of annual patient-years using interventions in each context. The costs were derived from a systematic review of the available evidence and a scenario analysis was conducted. The results show the dependence of the cost-effectiveness of HIVIAIDS interventions on the context of implementation and suggest the need for careful consideration, by South African policy makers, of the rural and urban contexts when allocating resources in HIVIAIDS interventions.
\end{abstract}

Keywords: HIVIAIDS, rural, urban, socio-economic, interventions, South Africa, modeling, Spectrum, projections.

\section{Introduction}

Despite a significant increase in resources committed to HIVIAIDS by the South African government since 2007 (Govender, 2009), the impact of the epidemic remains high. Therefore, efficient ways of allocating resources to maximise health benefits are needed. With the evidence that the effectiveness (Grassly, Garnett, Schwartlander, Gregson \& Anderson., 2001; Wegbreit, Bertozzi, DeMaria \& Padian, 2006) and, by implication, the cost of HIVIAIDS interventions depend on socio-economic contexts, the on-going question remains: Does the cost and effectiveness of an HIVIAIDS intervention in South Africa depend on whether the intervention is implemented in a rural area/context or an urban area/context? For if such dependence exists, South African policy makers would allocate resources to HIVIAIDS interventions according to how $t$ they are efficient in rural and urban contexts. This allocation, however, implies that the policy makers are aware of how cost-effectiveness estimates of several HIVIAIDS interventions compare in a rural context and an urban context, but this evidence has not been sufficiently produced in South Africa. Therefore, this paper aims to provide such estimates, through modeling.

An increased commitment of resources in the response to HIVIAIDS in South Africa followed a serious commitment to dealing with the epidemic by the South African government since 2007, after many years of controversial responses (Chigwedere, Seage, Gruskin, Lee \& Essex, 2008; Fassin \& Schneider, 2003; Johnson, 2004). In 2009, for example, the Zuma administration committed itself to the implementation of the five-year (2007-2011) National Strategic Plan (NSP), which focused on prevention and treatment. On World AIDS Day in 2009, President Zuma announced that, by April 2010, all children under one year who test HIV-positive would get ARV treatment, and that all pregnant women and patients with TB would receive ARV drugs if their CD4 count fell below 350 (Govender, 2009). In the same year, he launched an HIV counseling and testing (HCT) campaign with a target of 15 million (about one third of the population), by June 2010 (Cullinan \& Bodibe, 2010). By the time of this announcement, about seven million people were testing for HIV annually and 923000 were receiving treatment (Department of Health, 2010:15). In 2011, the government adopted early treatment policies which consisted of starting the provision of HAART therapy on patients when their CD4 count reached a threshold of 350. Implemented officially in April 2013 (Department of Health, 2013), this policy replaced the late

\footnotetext{
${ }^{1}$ The author acknowledges with thanks the financial support from Economic Research Southern Africa (ERSA). The views expressed are however those of the author and do not necessarily represent those of the funder, ERSA.
} 
treatment policy according to which patients started antiretroviral therapy (ART) when their CD4 count reached a threshold of 200. In the same year, universal coverage for adult patients was adopted. This consisted of providing HAART therapy to any patient who needs it according to the early treatment guidelines. On AIDS Day in December 2012, the deputy president of the country announced that about 1.9 million patients were on antiretrovirals (Xinhua, 2012). On the resources front, the HIVIAIDS budget in 2010 increased by 33\% over the previous year, and in 2011, it increased further by $30 \%$ (Motsoaledi, 2011).

These commitments have started paying off in terms of the reduction of the impact of HIVIAIDS. For instance, some studies have reported that survival among HIVIAIDS patients increased following the speed of scaling up antiretroviral therapy (Walensky et al., 2008). Other evidence revealed a decrease in secondary infections as result of the widespread rollout of antiretroviral drugs, which decreased viral loads in the infected population (Williams, Lima \& Gouws, 2011, Department of Health 2011:25). The rate of transmission from mother-to-child decreased from $8 \%$ in 2008 to $2.7 \%$ (Leach-Lemens, 2011). Furthermore, life expectancy increased from 56 years in 2008 to 60 years in 2011 (Xinhua, 2012). These benefits are not only limited to health outcomes but to broader socio-economic benefits given the link between health status and socio-economic life.

Though South Africa has recently seen a decrease in the impact of HIVIAIDS, the scale of the epidemic remains significant. The significance of the epidemic can be highlighted by reporting the most recent statistics. In 2012, for example, there were about 220,000 AIDS-related deaths and 110,000 new infections, while 5,685,424 people were living with HIV or AIDS (Actuarial Society of South Africa, 2011). The importance of the epidemic implies that available resources are managed efficiently in order to achieve the maximum health benefits possible from available resources. One way to manage efficiently these resources is to allocate them in HIVIAIDS interventions in rural and urban contexts according to how these interventions are most efficient in these contexts.

The allocation of resources in an HIVIAIDS intervention in a rural or an urban context based on the efficiency of such an intervention in each context requires, however, an estimation of the cost-effectiveness of that intervention to guide resources allocation. The cost-effectiveness of an HIVIAIDS intervention in a rural or an urban context is, however, uncertain and consequently the extent of the difference in the cost-effectiveness of a given intervention across a rural and an urban context is unknown. This is because such cost-effectiveness is a result of the interaction between the intervention and the context in which it is implemented. The uncertainty of cost-effectiveness in a given context starts with uncertainty regarding the impact of HIVIAIDS in that context, which leads to uncertainty concerning the effectiveness of an HIVIAIIDS intervention, that is, the reduction of the impact by the intervention in that context. The uncertainty regarding effectiveness leads in turn to uncertainty regarding costs of an intervention in a specific context.

The theory of the socio-economic determinants of health proposes that the impact of HIVIAIDS is lower in a context with higher socio-economic status (Marmot \& Wilkinson, 2005), for example, an urban context. This statement is based on the factors prevailing in a higher socio-economic status, such as, high levels of income and education, which are conducive to favorable health conditions and the avoidance of risky behaviours. This prediction of the theory of socioeconomic determinants of health implies that the impact of HIVIAIDS is higher in a rural context than in an urban context. Further implications of the theory are that the effectiveness of an HIVIAIDS intervention is lower in a rural context than it is in an urban context, based on the understanding that the effectiveness of an HIVIAIDS intervention is measured according to the extent to which it reduces the impact of HIVIAIDS. The lower effectiveness of an HIVIAIDS intervention in a rural context is due to the fact that an HIVIAIDS intervention does not have an effect on all factors which are responsible for the difference in the impact in a rural or an urban context.

The difference in the impact of HIVIAIDS across a rural context and an urban context, as a result of interaction between the intervention and the context, implies also a difference in costs. The difference in the cost of an intervention in rural and urban contexts can be grasped through the realization that an HIVIAIDS intervention earmarks specific activities related to the impact. For example, specific procedures are earmarked for patients whose CD4 count has reached a critical stage, while specific procedures are planned for patients with mild conditions. Since these HIVIAIDS impacts are caused by or originate from contextual factors, they prevail to a different extent in the rural context and an urban context. Consequently, since these health impacts influence the activities of an HIVIAIDS intervention, and since they may prevail to a different extent in a rural and an urban context, they may lead to differences in the cost of an HIVIAIDS intervention in these two contexts. According to the theory of the socio-economic determinants of health, a rural context is expected to be more impacted by the consequences of HIVIAIDS, such as new infections, AIDS sicknesses and AIDS-related deaths, than does an urban context.

It is to be noted, however, that the prediction of the theory of socio-economic determinants of health may not be always valid. In fact, the theory prediction is founded on the assumption that contextual factors influence average 
individual behaviours and attitudes towards HIVIAIDS intervention in a similar manner. Other theories, however, indicate that there are individual-specific factors which guide risky behaviours and attitudes towards interventions. Psychosocial theories, for example, explain that risk behaviours or attitudes towards HIV interventions depend on the ability and willingness to learn about change in such behaviours or attitudes (Rosenstock, 1974; Fishbein \& Ajzen, 1975; Ajzen 1991). Economic theory explains that unsafe risk behaviour (sexual behaviour/attitude towards health interventions) is based on a cost and utility analysis between sexual partners, or a cost and utility analysis of patients with respect to using a specific HIVIAIDS intervention (Becker 1976; Phillipson \& Posner, 1993; Levy, 2002; Oster, 2007; Bhattacharya, Bunzel, \& Qiao, 2007). Epidemiological theories focus less on individual behaviours, but on epidemic behaviour, thus highlighting the fact that the risk of infections and the effectiveness of interventions depend largely on HIV prevalence within particular contexts (Geoffard \& Phillipson, 1996). All these individual factors may prevail to a different extent in a rural context and an urban context, and may reverse the pattern predicted by the theory of the socio-economic determinants of health. For instance, a rural context may comprise people who predominantly adopt safe sexual behaviour because of individual respect for the norms in this context.

These theories imply that the way in which a rural and an urban context influence the cost-effectiveness of an intervention, is a result of interaction between the intervention and these theoretical factors in each context. Since the extent to which these theoretical factors prevail in a rural context and an urban context is uncertain and different; the extent to which they influence the impact of HIVIAIDS, the effectiveness and the cost of an HIVIAIDS intervention in a rural and an urban context, is also uncertain and different. This difference in the cost and effectiveness of an HIVIAIDS intervention in rural and urban contexts implies potential efficiency opportunities since the policy makers would allocate more resources to an intervention in a context where such an HIVIAIDS intervention results in a lower cost per health outcome, to increase efficiency.

Despite the potential to achieve efficiency by allocating resources in a rural context or an urban context according to the cost-effectiveness of an HIVIAIDS intervention in a specific context, this cost-effectiveness has not been estimated for major HIVIAIDS interventions in South Africa. The estimation of the cost-effectiveness of an HIVIAIDS intervention in a rural and an urban context would require a follow-up of patients in each context, which is costly, and can only provide cost-effectiveness estimates up to the point of follow-up while policy makers need to plan for the future. Consequently, this paper models the cost-effectiveness and compares such cost-effectiveness across a rural context and an urban context for major HIVIAIDS interventions in South Africa, notably prevention of mother-to-child transmission (PMTCT), HAART for adults and HAART for children, with a view to advising the policy maker on how to allocate resources in these contexts to increase efficiency.

\section{Methods}

In each context, the incremental cost-effectiveness ratio (ICER) of an HIVIAIDS intervention relative to usual care is calculated. The ICER of an HIVIAIDS intervention relative to usual care in a rural context is then compared to its ICER relative to usual care in an urban context.

The total costs and total health outcomes of an HIVIAIDs intervention and usual care in each of these contexts form the basis of the calculation of the ICER, which, in relation to usual care, is defined as the ratio of incremental costs to incremental effectiveness of an HIVIAIDS intervention. The total costs of an HIVIAIDS intervention in a context is the sum of the annual costs over the period 2007-2020, obtained by multiplying the annual number of patients by the average annual cost. It is assumed that in the absence of an HIVIAIDS intervention, patients in an HIVIAIDS intervention use usual care. Consequently, the total cost of usual care in a context is obtained by multiplying the annual average cost of usual care by the annual number of patients using an HIVIAIDS intervention. Total health outcomes of an HIVIAIDS intervention is the sum of annual health outcomes over the period 2007-2020 while total health outcomes of usual care are the sum of annual health outcomes over the period 2007-2020.

The incremental costs of an HIVIAIDS intervention over the period 2007-2020 is calculated as the difference between the total cost of an intervention and the total costs of usual care. The incremental effectiveness is calculated as the total health outcomes (number of HIV infections, deaths) of usual care minus the total health outcomes of HIVIAIDS interventions. Because the total number of infections and deaths are higher in the case of usual care than in the case of an intervention, the incremental effectiveness of an HIVIAIDS intervention consists of infections and deaths averted. The incremental costs and incremental effectiveness is used to calculate the ICER.

The annual number of patients in a rural context and in an urban context over the period 2007-2020 and the annual number of health outcomes are projected by Spectrum Policy Modeling System (SPMS) of the Futures Group 
International (Stover, 2004; 2009). The SPMS is a modular programme which integrates many models from which researchers can activate those relevant to their research questions. The SPMS has been extensively used to inform policy on many aspects at national levels (Rehle \& Shisana, 2003; Wood et al., 2000) or sub-national level (Mekonnen, Jegou, R., Continho, R.A., Nokes, J. \& Fontanet., 2002). One of the model's most recent uses was the estimation of the impact of expanded access to antiretroviral therapy in ten sub-Saharan countries, including South Africa (Anema et al., 2011). The SPMS is updated every two years to take account of the changes in the sector of HIVIAIDS (Stover, Walker, Grassly \& Marston, 2006). In this paper, the estimation of the cost-effectiveness required an activation of the population model, AIDS impact model and intervention model of SPMS. Though the model is prepopulated with South African input, it does not include inputs relevant to a rural or an urban context. So these input parameters had to be used in the three models.

For the population model, default United Nations (UN) Population Division model parameters for South Africa were adjusted to reflect the realities in the rural context and urban context in South Africa. The paper used population per age and gender for the base year, 1981, for the projection. The year was chosen as the base year for the demographic projection on the recommendation of the model builders to start projection two years before the first case of AIDS in the country, observed in 1983 (Abdool Karim \& Baxter, 2010:39). Life expectancy assumption was based on the UN Population Division statistics. With regard to age distribution of fertility, that is, how age groups share the number of births over time, it was assumed that a greater proportion of births from the young group occurred in the urban context relative to rural context, following a tendency of younger females to move to urban areas. Life expectancy was assumed to be higher among females than males (Statistics South Africa, 2010), but no differences were assumed concerning patterns of life expectancy across rural contexts and urban contexts over time, given the absence of evidence in this respect and given the evidence that HIV has been more prevalent in the urban population (Shisana \& Rehle, 2002). The total fertility rate in each area - the average number of children born to a woman in her lifetime -was also set at the South African total fertility rate due to the absence of data for the rural context and the urban context.

For the AIDS impact model, the study modeled prevalence in a rural and an urban context because the impact of HIVIAIDS has not been routinely reported in both contexts in South Africa. One study which reported the impact of HIVIAIDS in rural and urban areas was that of the HSRC (2002), which showed that the prevalence of HIVIAIDS was greater in urban areas than in rural areas. In this study, the urban areas comprised urban informal (townships) and urban formal (metropolitan) areas, while rural areas had two categories, tribal areas and farm areas. The present research combined urban informal and urban formal to comprise urban areas, and tribal and farm areas to comprise rural areas, and recalculated the prevalence of HIV in urban and rural areas based on the sample weights in each sub-area, and greater HIV prevalence in urban areas was used (HSRC/MRC/CADRE, 2002; 2005 \& 2008). The available evidence on prevalence in each area was used in the Estimation and Projection Package (EPP) to estimate annual infections in each context following procedures in other studies (see Rehle and Shisana (2003), for instance).

For the intervention model, the effectiveness evidence for HIVIAIDS interventions was used. In the absence of PMTCT data, the model assumed an infection rate of $30 \%$ in the rural context and of $28 \%$ in the urban context, based on the evidence regarding PMTCT in developing countries and differences in risk in rural and urban contexts (Decock et al., 2000; Department of Health, 2003). Following recent evidence, the infection rate under PMTCT interventions was assumed to be $5 \%$ in the urban context and adjusted to $6 \%$ in the rural context. For HAART interventions, the median time from infection to death was set at 10.5 years for adults in the urban context and to 9 years in the rural context. The median time from eligibility for treatment (at CD4 count 350) to death was assumed to be to be 7.9 years for adults in the urban context and 6.7 for adults in the rural context. The annual survival on ART was assumed to be $90 \%$ and $85 \%$ for adults in an urban and rural context, respectively, and $85 \%$ and $80 \%$ for children in an urban and rural context, respectively (UNAIDS 2009). Table 1 below provides a summary of the key demographic, AIDS impact, and intervention parameters used in the projections. 
Table 1. Key input parameters in the model

\begin{tabular}{|c|c|c|}
\hline \multicolumn{3}{|c|}{ Rural context } \\
\hline Baseline parameter & Base-case Value & Source \\
\hline Total population in 1981 & $14,500,000$ & UN population division \\
\hline Life expectancy at birth in 1981 & & \\
\hline Male & 55.1 & UN population division \\
\hline Female & 61.7 & UN population division \\
\hline Net migration & 9776 & UN population division \\
\hline $\begin{array}{l}\text { Perinatal transmission among breastfeeding women } \\
\text { with no intervention }\end{array}$ & $30 \%$ & Decock et al .(2000) \\
\hline Median time from HIV infection to death (no intervention & 9 years & $\begin{array}{l}\text { Assumption ( based on UNAIDS and } \\
\text { Department of Health, 2003) }\end{array}$ \\
\hline Prevalence rate (general population) & $8.3 \%$ & Based on Shisana \& Simbayi (2002) \\
\hline Net migration & 9776 & Statistics South Africa (2010) \\
\hline \multicolumn{3}{|c|}{ Urban context } \\
\hline Total population in 1981 & $15,200,000$ & UN population division \\
\hline Baseline life expectancy at birth in 1981 & & \\
\hline Male & 55.1 & UN population division \\
\hline Female & 61.7 & UN population division \\
\hline Net migration & 11283 & Statistics South Africa (2010) \\
\hline $\begin{array}{l}\text { Perinatal transmission among breastfeeding women } \\
\text { (no intervention ) }\end{array}$ & $28 \%$ & $\begin{array}{c}\text { Assumption (Based on the Department of } \\
\text { Health 2003) }\end{array}$ \\
\hline $\begin{array}{l}\text { Median time from infection to AIDS or deaths death (no } \\
\text { intervention) }\end{array}$ & 10.9 & UNAIDS (2009) \\
\hline HIV prevalence rate(general population) & 13.3 & Based on Shisana \& Simbayi (2002) \\
\hline
\end{tabular}

As would be expected, a high level of uncertainty is likely in this kind of modeling and as a result, before using the model projections for CE estimates in a rural context and an urban context, calibration is done. Specifically, the paper compares the sum of population data modeled by the paper in a rural context and in an urban context, to the South African population data modeled by ASSA2008 AIDS model (Actuarial Society of South Africa, 2011). The paper compares also the sum of HIV prevalence data modeled by the paper in a rural context and in an urban context, to the South African prevalence data modeled by ASSA2008 AIDS model (Actuarial Society of South Africa, 2011). Data modeled by this paper compares favorably with data modeled by ASSA2008 AIDS models as shown in Figure 1 and therefore can be used to model cost-effectiveness.
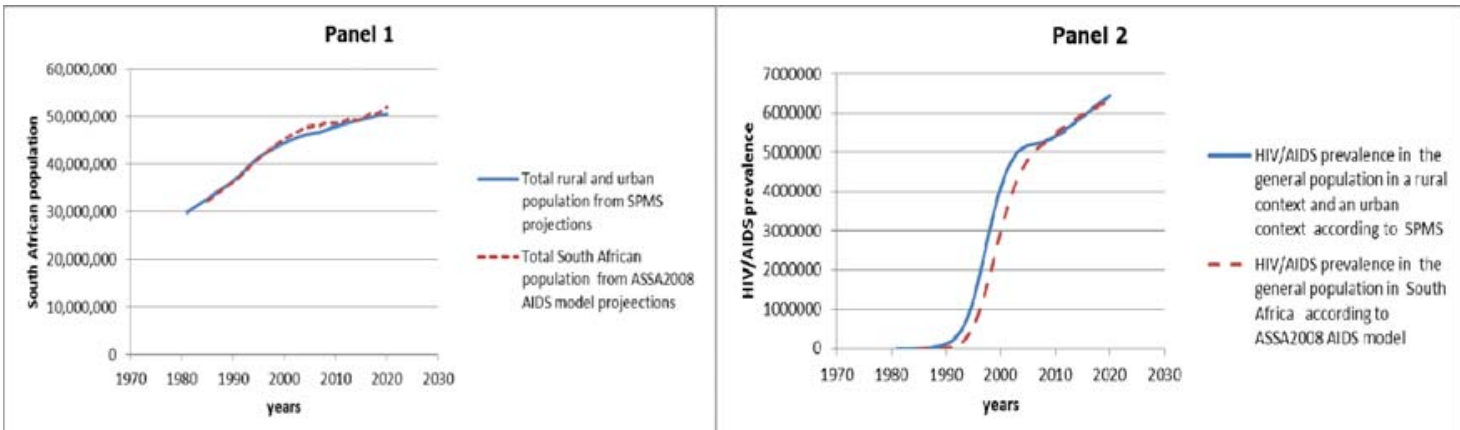

Figure 1. Comparison of modeled data to population data and prevalence

Given that not everyone accepts or adheres to treatment, the model assumes a coverage rate of $97 \%$ in each area, regardless of the intervention. The average annual costs per patient in each area is determined via a systematic review of the available evidence of the costs of modeled interventions, and the incremental cost-effectiveness ratios (ICER) of each intervention over usual care is estimated. The ICERs of an intervention is compared across a rural context and an urban context. All costs are estimated in 2007 constant US\$ to control for inflation. The time preference is taken 
into account by applying a 3\% discount rate as per recommendation by an expert panel on cost-effectiveness analysis (Gold, Siegel, Russell, Weinstein, 1996).

The baseline comparison is carried out using the parameters listed, the coverage rate of $97 \%$, the discount rate of $3 \%$, and the average annual cost of the base-case analysis. However, given the uncertainty underlying estimates, alternative discount rates of $0 \%$ and $7 \%$ are also used (Gold et al., 1996). With widespread antiretroviral therapy, patients' adherence to treatment is expected to drop based on the evidence of the increase in risky behaviours in developed countries arising from HAART-induced improvement in health status (McGowan et al., 2004). Since a drop in the adherence would affect the coverage rate of the interventions, scenario analyses of how the base-case conclusion changes when interventions coverage decrease to $80 \%$ in the rural areas or in the urban areas are conducted. In the first place, the changes in the base-case scenario were analyzed with assumptions of an $80 \%$ coverage rate in the rural areas, and then an $80 \%$ coverage rate in the urban areas. Finally, scenario analysis is conducted over the base-case scenario by using lower- and upper-bound estimates of costs in keeping with high variability and insufficiency in costestimates evidence.

\section{Results}

\subsection{Incremental costs}

The cost results are presented in Table 2. These costs are obtained by applying the average annual cost per patient to the number of patient-years using interventions over the period of analysis, as projected by SPMS.

Table 2 Comparisons of incremental costs of HIVIAIDS interventions in socio-economic contexts (2007-2020) in US\$

\begin{tabular}{|c|c|c|c|}
\hline \multicolumn{4}{|c|}{ Rural context } \\
\hline intervention & PMTCT & $\begin{array}{l}\text { HAART } \\
\text { ADULTS }\end{array}$ & $\begin{array}{l}\text { HAART FOR } \\
\text { CHILDREN }\end{array}$ \\
\hline Total cost USUAL CARE GP & $162,570,017$ & $892,784,873$ & $105,911,427$ \\
\hline Total cost USUAL CARE SP & $177,349,110$ & $982,063,361$ & $116,502,569$ \\
\hline Total cost of intervention GP & $322,328,839$ & $2,193,204,948$ & $364,473,357$ \\
\hline Total cost of intervention SP & $347,506,006$ & $2,312,134,705$ & $379,172,279$ \\
\hline Incremental costs GP & $159,755,822$ & $1,300,420,075$ & $258,561,930$ \\
\hline Incremental costs SP & $170,156,896$ & $1,330,071,344$ & $262,669,710$ \\
\hline $\begin{array}{l}\text { Incremental costs per 100,000 patient-years } \\
\text { (GP) }\end{array}$ & $10,580,584$ & $16,872,721$ & $13,221,339$ \\
\hline $\begin{array}{l}\text { Incremental costs per } 100,000 \text { patient-years } \\
\text { (SP) }\end{array}$ & & & \\
\hline \multicolumn{4}{|c|}{ Urban context } \\
\hline Total cost USUAL CARE GP & $73,895,462$ & $3,190,138,899$ & $155,043,316$ \\
\hline Total cost USUAL CARE SP & $88,674,555$ & $3,312,836,549$ & $212,427,251$ \\
\hline Total cost of intervention GP & $466,791,038$ & $5,673,879,395$ & $534,691,666$ \\
\hline Total cost of intervention SP & $510,737,895$ & $6,086,733,645$ & $606,564,596$ \\
\hline Incremental costs of intervention GP & $392,895,576$ & $2,483,740,496$ & $379,648,350$ \\
\hline $\begin{array}{l}\text { Incremental costs of intervention SP } \\
\text { Incremental cost per } 100,000 \text { patient-years }\end{array}$ & $422,063,340$ & $2,773,897,096$ & $394,137,345$ \\
\hline GP & $18,041,585$ & $12,257,920$ & $12,730,501$ \\
\hline $\begin{array}{l}\text { Incremental cost per } 100,000 \text { patient-years } \\
\text { GP }\end{array}$ & $19,380,956$ & $13,689,920$ & $13,216,351$ \\
\hline $\begin{array}{l}\text { IC per } 100,000 \text { patients GP rural /IC per } \\
100,000 \text { patients GP *100 }\end{array}$ & $58 \%$ & $137 \%$ & $103 \%$ \\
\hline
\end{tabular}

Source: Author, based on the results of SPMS projections. GP: government perspective; SP: societal perspective.

As Table 2 shows, the total costs of interventions are less in a rural context than they are in an urban context, and the incremental costs are also less in a rural context than they are in an urban context. Based on the government perspective's costs for example, Table 2 shows that HAART FOR ADULTS results in incremental costs of US\$ 
$1,300,420,075$ in a rural context while the corresponding number for an urban context is US $\$ 2,483,740,496$. These results are obvious given that an urban context, as defined in this paper, has a greater number of people living with HIVIAIDS. The comparison is more plausible if the difference in the population of patients across a rural context and an urban context is controlled for. Doing such a control by estimating the incremental costs per 100, 0000 patient-years, and Table 2 shows that per 100,000 patient-years, the incremental costs are generally higher in rural contexts, except for PMTCT. The incremental cost per 100,000 patient-years for PMTCT is US\$ $10,580,584$ in a rural context while it is US $\$ 18,041,585$ in an urban context, considering costs evaluated from the perspective of government. The last row of Table 2 shows the incremental costs in a rural context expressed as a percentage of the incremental costs in an urban context for each intervention. The row indicates that this percentage is 58\% for PMTCT while it is $137 \%$ and $103 \%$ for HAART FOR ADULTS and HAART FOR CHILDREN.

\subsection{Incremental effectiveness}

After comparing the incremental costs of each HIVIAIDS intervention relative to usual care across a rural context and an urban context, it is worth also comparing the incremental effectiveness of an HIVIAIDS intervention in a rural context and in an urban context. The effectiveness measures used in this comparison are infections and deaths averted by an HIVIAIDS intervention relative to usual care. Table 3 shows the results.

Table 3 Comparison of incremental effectiveness of HIVIAIDS interventions in socio-economic contexts (2007-2020)

\begin{tabular}{|l|c|c|}
\hline \multirow{2}{*}{ Intervention } & \multicolumn{2}{|c|}{ Effectiveness } \\
\cline { 2 - 3 } & Rural context & Urban context \\
\hline No intervention at all & & \\
Cumulative paediatric infections & 315,258 & 505,661 \\
Cumulative adult deaths & $2,119,490$ & $3,528,417$ \\
Cumulative paediatric deaths & 222,628 & 353,781 \\
\hline PMTCT & & \\
Total infections with PMTCT & 198,392 & 314,987 \\
Paediatric infections averted by PMTCT & 116,866 & 193,164 \\
HAART FOR ADULTS & $1,590,003$ & $2,077,634$ \\
Total adult deaths with HAART FOR ADULTS & 529,487 & $1,450,783$ \\
Total adult deaths averted by HAART ADULTS & & \\
HAART FOR CHILDREN & 108,523 & 170,376 \\
Total child deaths with HAART FOR CHILDREN & 114,105 & 183,405 \\
Total child deaths averted by HAART FOR CHILDREN &
\end{tabular}

Source: Author, based on the results of SPMS projections.

The results in Table 3 indicate that for each HIVIAIDS intervention, the number of infections (deaths) averted by an HIVIAIDS intervention relative to USUAL CARE is less in a rural context than it is in an urban context. For instance, PMTCT averts 116,866 infections over the period 2007-2020 in a rural context and 193,164 infections in an urban context over the same period. However, this finding needs to be considered bearing in mind that the size of the population of patients in these contexts is different. Since there are fewer patients in an HIVIAIDS intervention in a rural context, fewer infections and deaths averted are expected there. To control for the number of patients as in the analysis of incremental costs, estimates of incremental effectiveness are reported per 100,000 patient-years in each context. Table 4 shows the results. 
Table 4 Comparison of incremental effectiveness of HIVIAIDS Interventions in socio-economic contexts per 100,000 patient-years (2007-2020)

\begin{tabular}{|c|c|c|c|}
\hline \multirow{2}{*}{ HIV outcomes } & \multicolumn{3}{|c|}{ Rural context } \\
\hline & PMTCT & HAARTA & HAARTC \\
\hline A1. Total patient-years & 893,972 & \multirow{9}{*}{$\begin{array}{c}5,693,664 \\
529,487 \\
68,700\end{array}$} & \\
\hline B1. Total infections averted & 116,866 & & \\
\hline C1. Averted infections per 100,000 patient-years & 77,400 & & \\
\hline A1. Total patient-years & & & \\
\hline B1. Total adult deaths averted by HAARTA & & & \\
\hline C1. Averted infections per 100,000 patient-years & & & \\
\hline A1. Total patient-years & & & 663,813 \\
\hline B1. Total child deaths averted by HAARTC & & & 108,523 \\
\hline C1. Averted infections per 100,000 children-years & & & 58,500 \\
\hline \multirow{2}{*}{ 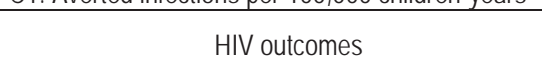 } & \multicolumn{3}{|c|}{ Urban context } \\
\hline & PMTCT & HAARTA & HAARTC \\
\hline A2. Total patient-years & $1,472,686$ & & \\
\hline B2. Total infections averted & 190,674 & & \\
\hline C2. Averted infections per 100,000 patient-years & 88,700 & & \\
\hline A2. Total patient-years & & $15,649,025$ & \\
\hline B2. Total adult deaths averted by HAART & & $1,450,783$ & \\
\hline C2. Averted infections per 100,000 patient-years & & 71,600 & \\
\hline A2. Total patient-years & & & 987,837 \\
\hline B2.Total child deaths averted by HAART & & & 183,405 \\
\hline C2. Averted infections per 100,000 children-years & & & 61,500 \\
\hline C1/C2*100 & $91 \%$ & $65 \%$ & $80 \%$ \\
\hline
\end{tabular}

Source: Author, based from SPMS projections.

As Table 4 indicates, modeled HIVIAIDS interventions are less effective in a rural context than they are in an urban context. Table 4 indicates that per 100,000 patient-years, PMTCT prevents less HIV infections in a rural context than it does in an urban context. In fact, the intervention prevents 7, 7400 infections in a rural context while it prevents 88,700 infections in an urban context over the period of analysis. Similarly, HAART FOR ADULTS and HAART FOR CHILDREN prevent fewer deaths in a rural context. Per 100,000 patient-years, HAART for ADULTS prevents 68,700 HIVIAIDS deaths in a rural context while it prevents about 71,600 HIVIAIDS deaths in an urban context. Corresponding statistics of HIVIAIDS deaths averted by HAART FOR CHILDREN are 58,500 (rural) and 61,500. Because less HIV infections and HIVIAIDS deaths are averted in a rural context, the incremental effectiveness in a rural context expressed as percentage of the incremental effectiveness in an urban context is less than $100 \%$.

\subsection{Cost-effectiveness}

In a cost-effectiveness analysis, however, it is important to analyse the additional costs arising from additional benefits, relative to usual care, of an HIVIAIDS intervention in each context. The ICER of an HIVIAIDS intervention relative to "usual care" is reported in a rural context and an urban context and the ICERs of the same intervention are compared across these two contexts, in the base-case comparison. Table 5 shows the results. 
Table 5. Comparisons of ICERs of HIVIAIDS interventions in socio-economic contexts (2007-2020), base-case value

\begin{tabular}{|l|l|l|l|}
\hline \multicolumn{5}{|c|}{ Rural context } \\
\hline Description & PMTCT & $\begin{array}{l}\text { HAART } \\
\text { ADULTS }\end{array}$ & $\begin{array}{l}\text { HAART } \\
\text { CHILDREN }\end{array}$ \\
\hline Total cost USUAL CARE GP & $162,570,017$ & $892,784,873$ & $105,911,916$ \\
Total cost USUAL CARE SP & $177,349,110$ & $982,063,361$ & $116,502,569$ \\
Total cost of intervention GP & $322,328,839$ & $2,193,204,948$ & $364,473,357$ \\
Total cost of intervention SP & $347,506,006$ & $2,312,134,705$ & $379,172,279$ \\
Incremental cost of intervention GP & $159,755,822$ & $1,300,420,075$ & $258,561,930$ \\
Incremental cost of intervention SP & $170,156,896$ & $1,330,071,344$ & $262,669,710$ \\
ICER GP & 1,367 & 2,456 & 2,266 \\
ICER SP & 1,538 & 2,806 & 2,379 \\
\hline \multicolumn{4}{|c|}{ Urban context } \\
\hline Total cost USUAL CARE GP & $73,895,462$ & $3,190,138,899$ & $155,043,316$ \\
Total cost USUAL CARE SP & $88,674,555$ & $3,312,836,549$ & $212,427,251$ \\
Total cost of intervention GP & $466,791,038$ & $5,673,879,395$ & $534,691,666$ \\
Total cost of intervention SP & $510,737,895$ & $6,086,733,645$ & $606,564,596$ \\
Incremental cost of intervention GP & $392,895,576$ & $2,483,740,496$ & $379,648,350$ \\
Incremental cost of intervention SP & $422,063,340$ & $2,773,897,096$ & $394,137,345$ \\
ICER GP & 2,034 & 1,712 & 2,070 \\
ICER SP & 2,051 & 1,912 & 2,149 \\
ICER rural GP/ICER urban GP*100 & $67 \%$ & $143 \%$ & $109 \%$ \\
\hline
\end{tabular}

Source: Author, based on the results of SPMS projections. GP: government perspective, SP: societal perspective. The percentage in the last row Table 5 reflects the value of the ICER in a rural context as percentage of the ICER in an urban context for a given HIVIAIDS intervention.

The results in Table 5 indicate that PMTCT is more cost-effective in a rural context than it is in an urban context. From a government perspective's costs, the ICER of PMTCT in a rural context is US\$1,367 per infection averted in a rural context while it is US\$2,034 in an urban context. In terms of relative cost-effectiveness, the ICER of PMTCT in a rural context is $67 \%$ of its ICER in an urban context. Therefore, PMTCT is more cost-effective in a rural context than it is in an urban context.

HAART FOR ADULTS and HAART FOR CHILDREN are less cost-effective in a rural context than they are in an urban context. Their ICERs are US\$2,456 and US\$2,266 respectively per death averted in a rural context while these ICERs are US $\$ 1,712$ and US $\$ 2,070$ per death averted in an urban context. In terms of relative cost-effectiveness, the ICERs of HAART FOR ADULTS and HAART FOR CHILDREN in a rural context are $143 \%$ and $109 \%$ of their respective ICERs in an urban context. This result shows that HAART FOR ADULTS and HAART FOR CHILDREN are relatively less cost-effective in a rural context.

Furthermore, the results in Table 5 show the extent to which CE estimates vary across HIVIAIDS interventions. The extent of CE in any context is measured by how far the ICER of an HIVIAIDS intervention in one context expressed as percentage of the ICER of that intervention in another context, is to $100 \%$. The last row of Table 5 shows that the percentage of the ICER of an intervention in a rural context, measured from the perspective of government, relative to the ICER of the same intervention in an urban context varies across modeled interventions. A given intervention would be equally effective in a rural context and an urban context if this percentage is $100 \%$. Since reported percentages of the three interventions are away from $100 \%$ to a different extent, the extent of CE of modeled interventions depends on the context as shown in Table 6. 
Table 6. Comparison of the extent of cost-effectiveness across HIVIAIDS interventions in socio-economic contexts (in US\$/outcome)

\begin{tabular}{|l|l|l|l|}
\hline Intervention & $\begin{array}{l}\text { ICER in a rural } \\
\text { context }\end{array}$ & $\begin{array}{l}\text { ICER in an } \\
\text { urban context }\end{array}$ & $\begin{array}{l}\text { ICER in a rural context as \% } \\
\text { of the ICER in an urban } \\
\text { context }\end{array}$ \\
\hline PMTCT & 1367 & 2034 & 54 \\
HAART FOR ADULTS & 2456 & 1712 & 151 \\
HAART FOR CHILDREN & 2266 & 2070 & 109 \\
\hline
\end{tabular}

Source: Author, based on the results of SPMS projections

The results in Table 6 illustrate that the CE of HIVIAIDS interventions has no specific trend across a rural context and an urban context as some HIVIAIDS interventions are more cost-effective in a rural context, while for others, the opposite is true. The results also, in column 4 of Table 6 , show that the extent of CE is different across interventions.

These results are subjected to sensitivity analysis. One of the key issues likely to affect the effectiveness of HIVIAIDS interventions in lifelong HAART therapy is a decrease in treatment adherence. As this decrease would affect the coverage of HIVIAIDS interventions, the paper analyses the effect of a $20 \%$ decrease in coverage (due to a possible decrease in adherence) on the results of the base-case comparison. The results are presented in Table 7

Table 7. Effect of a decrease in coverage rate by $20 \%$, government's perspective.

\begin{tabular}{|c|c|c|c|c|}
\hline \multicolumn{5}{|c|}{ Adherence drop by $20 \%$ in rural context } \\
\hline \multicolumn{5}{|c|}{ Rural context } \\
\hline & & PMTCT & HAART FOR ADULTS & $\begin{array}{ll}\text { HAART } & \text { FOR } \\
\text { CHILDREN } & \end{array}$ \\
\hline Base case & ICER GP & 1,367 & 2,456 & 2,266 \\
\hline Drop 20\% & ICER GP & 1,417 & 2,512 & 2,313 \\
\hline \multicolumn{5}{|c|}{ Urban context } \\
\hline Base-case & ICER GP & 2,034 & 1,712 & 2,070 \\
\hline Base-case & ICER GP & 2,034 & 1,712 & 2,070 \\
\hline \multicolumn{5}{|c|}{ Adherence drop by $20 \%$ in urban context } \\
\hline \multicolumn{5}{|c|}{ Rural context } \\
\hline & & PMTCT & HAART FRO ADULTS & $\begin{array}{l}\text { HAART } \\
\text { CHILDREN }\end{array}$ \\
\hline Base- case & ICER GP & 1,367 & 2,456 & 2,266 \\
\hline Base-case & ICER GP & 1,367 & 2,456 & 2,266 \\
\hline \multicolumn{5}{|c|}{ Urban context } \\
\hline Base case & ICER GP & 2,034 & 1,712 & 2,070 \\
\hline Drop 20\% & ICER GP & 2,101 & 1,802 & 2,145 \\
\hline
\end{tabular}

Source: Source: Author, based on the results of SPMS projections. GP: government perspective costs, SP: societal perspective costs.

A decrease in the adherence by $20 \%$ in one context does not affect the result of the base-case estimates in another context but only estimates in the context in which the decrease takes place. For instance, a decrease in adherence in a rural context by $20 \%$ does not affect the ICER of PMTCT in an urban context. The ICER of PMTCT in an urban context remains equal to the ICER of the base-case comparison, that is, US\$2034. When there is a decrease in adherence in a rural context by $20 \%$ however, the ICER of HIVIAIDS interventions in a rural context increases. For instance, the ICER of PMTCT increases from US\$ 1367 to US\$1417. An implication of this result is that effectiveness of modeled HIVIAIDS interventions decrease more than the decrease in the cost as a result of a reduction in the coverage by $20 \%$.

Similarly, the decrease in adherence by $20 \%$ in urban contexts does not affect the results of the base-case comparison in a rural context. However, this decrease in adherence increases the ICER of HIVIAIDS interventions in an urban context. Table 7 shows that the ICER of PMTCT in an urban context, for instance, increases from US $\$ 2,034$ to 
US $\$ 2,101$. Again, this observation signifies that, as a result of the decrease in adherence by $20 \%$ in a given context, the decrease in the effectiveness is more than the decrease in the costs. However, even though the decrease in the adherence affects the CE of an intervention in a context in which the decrease takes place, it does not affect the comparability of CE of HIVIAIDS interventions across contexts. Therefore the results of the base-case comparison are robust to the change in the adherence.

The discount rates used have been considered as factors influencing the cost-effectiveness results. Consequently, it was recommended (Gold et al., 1996) to check how the conclusions of the base-case comparison change with different discount rates. To this end, cost-effectiveness results of the base-case comparison were reproduced using different discount rates. Table 8 shows the ICER of HIV with different discount rates. The Table shows as expected, that the ICERs of HIVIAIDS interventions decrease as the discount rates increase. The results show for example that with a discount rate of $3 \%$, the ICER of PMTCT of US\$1,367 (measured from the government's perspective) in a rural context changes to US $\$ 1,089$ with a discount rate of $7 \%$. The same patterns in the change of ICER are observed in an urban context. While these changes are observed for all modeled interventions, they do not change the base-case conclusion.

Table 8. Effect of using different discount rates

\begin{tabular}{|l|l|l|l|l|l|l|l|}
\hline \multirow{2}{*}{$\begin{array}{l}\text { Discount } \\
\text { rate }\end{array}$} & \multicolumn{9}{|l|}{ Rural context } & Urban context \\
\cline { 2 - 7 } & ICER & PMTCT & HAART & $\begin{array}{l}\text { HAART FOR } \\
\text { CHILDREN }\end{array}$ & PMTCT & $\begin{array}{l}\text { HAART FOR } \\
\text { ADULTS }\end{array}$ & $\begin{array}{l}\text { HAART FOR } \\
\text { CHILDREN }\end{array}$ \\
\hline $0 \%$ & ICER GP & 1,654 & 2,713 & 2,250 & 2,219 & 1,888 & 2,315 \\
& ICER SP & 1,805 & 2,915 & 2,480 & 2,311 & 1,801 & 2,429 \\
$3 \%$ & ICER GP & 1,367 & 2,456 & 2,266 & 2,034 & 1712 & 2,070 \\
& ICER SP & 1,538 & 2,086 & 2,379 & 2,051 & 1,912 & 2,149 \\
$7 \%$ & ICER GP & 1,089 & 1,615 & 1,714 & 1,609 & 1,579 & 2,567 \\
& ICER SP & 1,188 & 1,745 & 1,815 & 1,723 & 1,562 & 1,697 \\
\hline
\end{tabular}

Source: Author, based on the results of SPMS projections. ICER is measured as costs per infection averted for PMTCT, per death averted for HAART interventions. GP: government perspective costs, SP: societal perspective costs

Finally, the insufficiency of cost data evidence required a scenario analysis of what would happen to the base-case conclusions when the lower and upper bound estimates of costs were used. Table 9 shows the results.

Table 9. Effect of using lower and upper bound cost estimates

\begin{tabular}{|c|c|c|c|}
\hline \multicolumn{4}{|c|}{ Lower bound estimates } \\
\hline \multicolumn{4}{|l|}{ Rural context } \\
\hline Intervention & PMTCT & HAART FOR ADULTS & HAART FOR CHILDREN \\
\hline ICER GP & 685 & 632 & 736 \\
\hline ICER SP & 752 & 759 & 753 \\
\hline \multicolumn{4}{|c|}{ Urban context } \\
\hline Intervention & PMTCT & HAART & HAARTC \\
\hline ICER GP & 1,050 & 803 & 655 \\
\hline ICER SP & 1,115 & 830 & 690 \\
\hline \multicolumn{4}{|c|}{ Upper bound estimates } \\
\hline \multicolumn{4}{|c|}{ Rural context } \\
\hline Intervention & PMTCT & HAART FOR ADULTS & HAART FOR CHILDREN \\
\hline ICER GP & 2,815 & 1,265 & 2,150 \\
\hline ICER SP & 2,912 & 1,560 & 2,250 \\
\hline \multicolumn{4}{|c|}{ Urban context } \\
\hline ICER/Intervention & PMTCT & HAART FOR ADULTS & HAART FOR CHILDREN \\
\hline ICER GP & 1,850 & 1,315 & 2,400 \\
\hline ICER SP & 2,856 & 1395 & 2,420 \\
\hline
\end{tabular}

Source: Author, based on the results of SPMS projections. Keys: GP: government perspective costs, SP: societal perspective costs 
The results in Table 9 show that the use of lower and upper bound cost estimates changes some of the conclusions in the base-case analysis. For instance, in the base-case comparison, PMTCT was more cost-effective in a rural context than it was in an urban context. While the intervention remains more cost-effective in a rural context with the use of lower bound cost estimates, the opposite is true when upper bound cost estimates are used. Table 9 shows that with upper bound estimates of costs, the ICER of PMTCT in a rural context becomes US\$2,815 per infection averted while it is US\$ 1,850 per infection averted in an urban context. This result makes PMTCT more cost-effective in an urban context and this conclusion is different from the conclusion in the base-case comparison. The change in the CE comparability of PMTCT across a rural context and an urban context as a result of a change in cost estimates applies to other modeled interventions. HAART FOR ADULTS which was more cost-effective in an urban context than in rural context becomes less cost-effective when lower bound cost estimates are used as shown in Table 9. As the results in the latter Table change many of the conclusions reached by the base-case comparison, the results are not robust to a change in estimates of cost.

\section{Discussion and conclusion}

\subsection{Discussion}

This paper set out to find out whether the CE estimates of HIVIAIDS interventions changes from a rural context to an urban context in South Africa. Estimates obtained through modeling with Spectrum Policy Modeling System, which allowed the interaction between HIVIAIDS interventions and these contexts to be taken into account, revealed that the CE of an HIVIAIDS intervention indeed depends on the context of its implementation. Briefly, the paper found that a given HIVIAIDS intervention results in different CE estimates depending on whether it is implemented in a rural context or an urban context. In particular, the paper found that the ICER of PMTCT in a rural context expressed as a percentage of its ICER in the urban context is $67 \%$. In contrast, the ICERs of HAART FOR ADULTS and HAART FOR CHILDREN in a rural context are $143 \%$ and $109 \%$ of the ICERs of the same interventions in an urban context.

Bearing in mind that the ICER of an intervention is the additional costs per additional health outcomes of an intervention as compared to "usual care", the lower the ICER, the more cost-effective is the intervention. Linking this information to the results above, it is clear that an HIVIAIDS intervention is not equally cost-effective across socioeconomic contexts. If an intervention was equally cost-effective across contexts, its ICER in one context as a percentage of its ICER in another context would be $100 \%$. The percentage was less that $100 \%$ for PMTCT, suggesting that the latter intervention is more cost-effective in a rural context. In contrast, since the percentage was higher for HAART for adults and HAART for children, the latter intervention is more cost-effective in the urban context.

The results have shown that the extent of $\mathrm{CE}$ is different across interventions in socio-economic contexts. Not only is CE of an HIVIAIDS intervention different in socio-economic contexts, but also the extent of the difference varies across modeled HIVIAIDS interventions. For instance, the results indicate that HAART for adults has the greatest extent of CE in the context in which it is more cost effective (the relative ICER is 143\%). These results have provided ample evidence that the CE of HIVIAIDS interventions depends on the context, answering our research question on whether or not the CE of an HIVIAIDS intervention depends on the context and if so, to what extent. The results have indicated that CE and its extent indeed depend on the context and on the type of HIVIAIDS intervention.

Interpreting the meaning of these results requires reverting back to the methodology used in this analysis. After controlling for the difference in the sizes of patients, the costs and effectiveness results should have been the same across contexts. The fact that the results are not the same can be explained by the influence of the interaction between HIVIAIDS interventions and contextual and individual factors. Theory indicates that those individual risk behaviours can be shaped by the contexts in which people live (see for instance among many others, Marmot \& Wilkinson, 2005; Phillipson and Poster, 1993; Ajzen, 1991). Since these factors prevail to a different extent and in complex patterns in modeled contexts, and a standard HIVIAIDS intervention does not necessarily target all these factors, the CE of an HIVIAIDS intervention across a rural context and an urban context is doomed to be different.

These results have some precedents in the literature. Veguet and Wash (2012) compared the CE of microbicides in South Africa and the US. The results over one year for a hypothetical population of patients showed that the cost and effectiveness in the US and South Africa were different. Over one year, it was estimated that the intervention prevents 1,908 new infections in South Africa, and 21 new infections in the US. In South Africa, the saving of the intervention was estimated at US\$6,712 per infection averted while no saving was reported in the US. A related study by Dowdy et al. (2006) compared the CE of nitrile female condom across South Africa and Brazil, which are comparable in in terms of 
socio-economic status and risk behaviours. The results, over a period of three years on 1,000 hypothetical patients, were that expanding female condom use to $10 \%$ of the adult females would avert 604 infections at US\$20,683 in Brazil, while in South Africa, 9,577 infections could be averted at US $\$ 985$ per infection averted. While these studies constitute an important contribution to the literature, they aimed to inform international policy makers rather than South African ones.

Finally, although the findings of this study appear to be significant with respect to policy making in resource allocation, they need to be understood in the context of the evidence used in the analysis. While scenario analysis on the discount rates and the coverage of interventions did not seem to reveal a change in the conclusions of the base-case analysis, the conclusions were very sensitive to the cost assumptions. Given that the sources of estimates of the cost of the different interventions compared were inadequate, it is likely that the results might not be accurate. This calls for more studies on the cost analysis of health care interventions in general and HIVIAIDS interventions in particular, if policy on HIVIAIDS interventions is to be founded on solid evidence. Previous studies have also pointed to this need in Africa (see Creese et al., 2002, for example).

\section{Conclusion}

This study used the best available evidence in South Africa to compare the cost-effectiveness of HIVIAIDS interventions in a rural context and in an urban context over the period 2007-2020. The analysis was conducted by means of Spectrum Policy Modeling System together with demographic, epidemic and intervention parameters for the urban and rural contexts. The conclusions of the study were that the cost-effectiveness of HIVIAIDS interventions depended on the socioeconomic context of intervention. While it was not possible to determine the factors underlying difference in costeffectiveness across rural and urban contexts, the study found it important for policy makers to start considering allocations of resources in HIVIAIDS interventions on the basis of cost-effectiveness evidence of such interventions in these contexts. For such a policy drive to be successful, more cost analysis studies are needed.

\section{References}

Abdool Karim S.S and Baxter C. (2010). Introduction. In: HIV/AIDS in South Africa., ed. S.S Abdool Karim and Q.A Abdool Karim. Cambridge. Cambridge University Press.

Actuarial Society of South Africa (ASSA). (2011). ASSA2008 AIDS model <www.actuarialsociety.org.za > (accessed November,20, 2011 2012)

Ajzen, I. (1991). Theory of planned behaviour. Organisational Behavior and Human Decision Process, 50, 179-211.

Anema A, Au-Yeung CG, Joffres, M et al.. (2011). Estimating the impact of expanded access to antiretroviral therapy on maternal, paternal and double orphans in Sub-Saharan Africa, 2009-2020. AIDS Research and Therapy 8:13. Available at http://www. aidsresearchtherapy.com/content/8/1/13

Becker, G. (1976). The Economic Approach to Human Behavior. Chicago.University of Chicago Press.

Bhattacharya, C., Bunzel, H., \& Qiao, X.. (2007). Unsafe sex, AIDS and development, Staff General Research Papers, No.12832, Department of Economics, lowa State University.

Chigwedere, P., Seage, G. R., Gruskin, S., Lee, T. H. \& Essex, M. (2008). Estimating the lost benefits of antiretroviral drug use in South Africa. Journal of Acquired Immune Deficiency Syndrome, 49(4), 410-415.

Creese A, Floyd K, Alban A et al.. (2002). Cost-effectiveness of HIVIAIDS interventions in Africa: A systematic review of the evidence. Lancet, 359, 1635-1642.

Cullinan, K., \& Bodibe, K. (2010). Country launches massive HIV testing Campaign Health-e, April 2010. Retrieved from www.healthe.org.za .

Decock, K.M., Fowler, M.G., Mercier, E., DeVincenzi, I., Saba, J., Hoff, E., Alnwick, D. J., Rogers, M., Shaffer, N. (2000). Prevention of mother-to-child HIV transmission in resources -poor countries: translating research into policy and practice. JAMA, 283, 11751182

Department of Health. (2003). South Afrian Demographic and Heallth Surveys. Pretoria. http://www.info.gov.za/view/DownloadFile Action?id=90143 ( accessed January 15, 2013)

Department of Health (2010). Country Progress Report on the Declaration of Commitment on HIV/AIDS. Report to the United Nations General assembly (UNGASS). Country Report. March 2010. Pretoria

Department of Health. (2011). Progress in HIV incidence estimation methods in South Africa. http://www.doh.gov.za/docs/reports/2012 lepicomments.pdf (accessed December 15,2012)

Department of Health. (2012). The South African antiretroviral treatment guidelines. Pretoria. http://www.doh.gov.za/docs/policy/2013 IART_Treatment_Guidelines_Final_25March2013.pdf (accessed on May 20, 2013)

Fassin, D. \& Schneider, H. (2003). The politics of AIDS in South Africa : Beyond the controversies. Biomedical Journal, 326, $495-497$. 
Fishbein, M. \& Azjen, I. (1975). Belief, Attitude, Intention and Behavior: An Introduction to Theory and Research Reading. Chicago. Addison-Wesley.

Geoffard P Y, Phillipson T. (1996) Rational epidemics and their public control. International Economic Review 7(3), 603-624.

Gold M E, Siegel JE, Russel, LB et al. (1996). Cost-effectiveness in Health and medicine. New York: Oxford University Press.

Govender, P. (2009). South Africa to expand AIDS treatment-Zuma. Reuters December 1. Accessed at http://uk.reuters.com/article /2009/12/01, on 10/01/2012.

Grassly, N. C., Garnett, G.P., Schwartlander, B., Gregson, S. \& Anderson, R. M. (2001). The effectiveness of HIV prevention and the epidemic context. Bulletin of the World Health Organisation, 79(12), 1121-1132

HSRC/MRC/CADRE. (2009). Nelson Mandela HSRC Study of HIVIAIDS. South African National HIV prevalence, Incidence, Behaviour and Communication Survey 2008. A Turning Tide among Teenagers. Cape Town: HSRC Press.

HSRC/MRC/CADRE. (2005). Nelson Mandela/HSRC Study of HIVIAIDS. South African National HIV prevalence, Incidence, Behaviour and Communication Survey 2008. A Turning Tide among Teenagers. Cape Town: HSRC Press.

HSRC/MRC/CADRE. (2009). South African National HIV prevalence, Incidence, Behaviour and Communication Survey 2008. A Turning Tide among Teenager. Cape Town: HSRC Press.

Johnson, K. (2004). The politics of AIDS policy development and implementation in post Apartheid South Africa. Africa Today, 51 (2), 107-128.

Leach-Lemens, C. (2011). South Africa's PMTCT Programme Reduces Mother-to-Child Transmission to under 4.\%. AIDSMap, 19 July. Accessed at http://www. aidsmap.com/South-Africas-PMTCT-programme-reduces-mother-to-child-transmission-to- under-4/page /1880446/, on 15/04/2012.

Levy, A (2002), A lifetime portfolio of risky and risk-free sexual behaviour and the prevalence of AIDS. Journal of Health Economics, 21(6), 993-1007.

Marmot, M. \& Wilkinson, R. (2005). Social Determinants of Health. Oxford. Oxford University Press.

McGowan, J, P., Shah, S.S., Ganea, C.E., Blum, S., Ernst, J.E., Irwin, K L.....Weidle, P.J. (2004). Risk behavior for transmission of human immunodeficiency virus (HIV) among HIV-seropositive individuals in an urban setting. CID, 38(January), 122-127

Mekonnen Y, Jegou R, Continho RA et al. (2002). Demographic impact of AIDS in low-fertility urban African setting: Projections for Addis-Ababa, Ethiopia. Journal of Health and Population Nutrition, 20(2), 120-129.

Motsoalidi A. (2011). How we are Re-engaging the Health System. Health budget vote policy speech presnted at the National Assembly, South Africa. < www.doh.gov.za.>( accessed February 20, 2013)

Oster, E. (2007). HIV and sexual behaviour change: Why not Africa?, NBER Working Paper, No. 13049

Phillipson, T.\& Posner, R. (1993). Privates Choices and Public Health: The AIDS Epidemic in an Economic Perspective. Cambridge. Havard University Press.

Rehle TM, Shisana O. (2003). Epidemiological and demographic HIVIAIDS projections. African Journal of AIDS Research, 2(1), 1-8.

Rosenstock, I M. (1974). Historical origins of the health belief model. Health Educ Monograph, 2, 238-335..

Statistics South Africa. (2010). Mid-year Population Estimates, 2010. [Publication or where accessed details?]

Stover J, Walker N, Grassly NC et al. (2006). Projecting the demographic impact of AIDS and the number of people in need of treatment: Update to Spectrum projections packages. Sexually Transmitted Infections, 82(Suppl III

Stover J. (2004). Projecting the demographic consequences of adult HIV prevalence trends. The Spectrum Projection Package. Sexually transmitted Infections, 80 (Suppl I),

Stover J. (2009). AIM: A computer program for making HIVIAIDS projections and examining the demographic and social impacts of AIDS. Washington, DC: Futures Group International, Health Policy Initiative, Task Order 1.

UNAIDS. (2009). Spectrum 2009, Estimates and Projections of National HIVIAIDS epidemic. [Power Point presentation.] Geneva: UNAIDS.

Walensky RP, Wood R, Weinstein MC et al.. (2008). Scaling up antiretroviral therapy in South Africa: The impact of speed on survival. Journal of Infectious Diseases 197, 1324-1332.

Wegbreit, J., Bertozzi, S., DeMaria, L.M., \& Padian, N.S. (2006). Effectiveness of HIV Prevention Strategies in Resource-Poor Countries:Tailoring the Intervention to the Context. AIDS, 20, 1217-1235

Wilkinson D, Floyd K, Gilks FC. (2000). National and provincial estimated costs and cost-effectiveness of a programme to reduce mother-to-child HIV transmission in South Africa. South African Medical Journal 90(8), 794-798.

Williams B, Lima U, Gouws E. (2011). Modeling the impact of antiretroviral therapy on the epidemic of HIV. Current HIV research 9:000000. Accessed at http://www.ttea.info/images/Williams_CHIVR.pdf on 13/12/2013.

Wood E, Braitsein P, Montaner J et al. (2000). Extent to which low-level use of antiretroviral treatment could curb the AIDS epidemic in Sub-Saharan Africa. Lancet ,355, 2095-2100.

Xinhua A. (2012). Antiretroviral treatment contributes to improved life expectancy in South Africa. < http://news.xinhuanet.com/english /world/2012-12/01/c_132012813.htm> (accessed December 20,2012). 